RESEARCH PAPER

\title{
Smoking behaviour among young adults: beyond youth prevention
}

\section{Hammond}

Correspondence to:

David Hammond,

Department of Psychology,

University of Waterloo,

200 University Avenue

West, Waterloo, Ontario, N2L 3G1, Canada;

dhammond@uwaterloo.ca

Received 4 August 2004 Accepted 20 January 2005
Objective: There is a widespread assumption that smoking behaviour is largely established by the age of 18 years. As a result, smoking prevention has focused almost exclusively upon youth. However, recent trends suggest that young adulthood may be an important-and largely overlooked-period in the development of regular smoking behaviour. The current study sought to examine patterns of tobacco use among young adults (aged 18-29 years) and to address the implications for tobacco control policy.

Design: Data are presented from the 2003 Canadian Tobacco Use Monitoring Survey, a national survey of smoking behaviour ( $\mathrm{n}=10559$, response rate $89 \%$ ).

Main outcome measures: Measures of smoking behaviour, smoking initiation, susceptibility to smoking, and occupational status.

Results: A total of 1.4 million or $28 \%$ of young adults in Canada currently smoke, the highest proportion among all age groups. The prevalence of daily smoking rose from $8 \%$ among youth to $22 \%$ among young adults, and approximately one fifth of smokers tried their first cigarette after the age of 18 years. Smoking behaviour among young adults was also distinct from older smokers: young adults were more likely to be occasional smokers and reported lower daily consumption. Finally, smoking prevalence and cessation rates varied substantially within subgroups of young adults, as characterised by occupational setting. Conclusions: Dramatic increases in the proportion and intensity of smoking occurs after the age of 18 years. Smoking behaviour among young adults is distinct from both youth and older adults, and warrants immediate attention from the public health community.
$\mathrm{T}$ here is a widespread assumption within the public health community that smoking behaviour is largely fixed by the age of 18 years. This assumption is firmly embedded within tobacco control strategy: for the past 30 years, smoking prevention programmes have been focused almost exclusively upon youth, mainly within the school setting. ${ }^{1}$ This approach is largely based upon the seminal research finding that virtually all smokers begin smoking before the age of $18 .^{23}$ However, research on contemporary patterns of smoking among young adults is beginning to challenge the wisdom of this strategy, along with traditional assumptions about patterns of smoking in adulthood.

Smoking behaviour may not be nearly as fixed or stable among young adults as is generally assumed. In recent survey data, as many as one fifth of smokers reported starting smoking after the age of 18-a substantial increase over historical norms. ${ }^{45}$ Even among smokers who first try smoking in their youth, "regular" or daily smoking may not develop until much later, typically between the ages of 20-21. ${ }^{5}$ These recent trends are consistent with documents from the tobacco industry that depict the transition from smoking the first cigarette to becoming a "confirmed" smoker as a series of stages that may extend to age $25 .{ }^{67}$ As industry research points out, the progression to confirmed smoker is also accompanied by important increases in consumption: "The 10 years following the teenage years is the period during which average daily consumption per smoker increases to the average adult level. ${ }^{\prime 7}$ There also appears to be a relatively higher proportion of occasional smokers among young adults, as compared to older smokers, with considerable shifting between daily and non-daily use. ${ }^{4}$ However, because of a lack of research, it is unclear to what extent these trends represent stable, meaningful shifts in smoking initiation and patterns of tobacco use.

The variable patterns of tobacco use among young adults may partly be explained by the significant life transitions experienced by young adults. ${ }^{8}$ Young adulthood often includes dramatic changes in social networks, living arrangements, and school and work settings, that may increase susceptibility to smoking. Research from RJ Reynolds describes this phenomena:

\begin{abstract}
"These years of transition represent a shift between the comfort of the high influence of the peer group, and relative structure in life, to the development of one's own personal, social, and occupational goals. For some, smoking seems to fulfill the function during teens of uniting one with the all-important peer group. In adulthood, it may be used to ease the feelings of stress created by the pursuit of one's goals. Smoking, for a young adult, may fulfill both roles, providing a concrete balance at a time when life is chaotic and stressful. ${ }^{\prime \prime 9}$
\end{abstract}

Put another way, young adulthood may render young adults more susceptible to tobacco industry marketing. The tobacco industry has developed marketing strategies not only to encourage smoking initiation and experimentation, but also to carry smokers through the stages to established smoker. ${ }^{10}$ The industry has been particularly effective in integrating tobacco advertising into the work and social setting of young adults. ${ }^{11-13}$ To this end, tobacco companies are increasingly using alternative media and more decentralised marketing activities to engage young adults and circumvent advertising restrictions. ${ }^{14}{ }^{15}$ In Canada, as elsewhere, tobacco companies have developed their own nightclub events and multimedia communities as marketing vehicles with particular appeal to young adults. ${ }^{16}$ As the youngest legal targets of tobacco advertising, young adults also provide the industry with access to youth. Indeed, evidence from a variety of sources indicates that industry advertising and promotions ostensibly aimed at young adults continue to reach and resonate with youth. ${ }^{17-19}$ 
In contrast to tobacco companies, the public health community has paid scant attention to smoking behaviour among young adults. A recent review of prevention and cessation programmes found a serious lack of initiatives directed at young adults, mainly due to the traditional focus upon youth. ${ }^{1}$ This bias is also reflected at the policy and planning level. Young adults are almost entirely absent from Canada's Federal Tobacco Control Strategy, ${ }^{20}$ as is the case with policy and practice statements from other countries. ${ }^{21}{ }^{22}$ Nor have young adults been a priority for research. With the notable exception of the Harvard College Alcohol Survey, ${ }^{23}$ few studies have directly examined smoking behaviour among young adults or even analysed young adults separately in population based studies. In short, young adults have been almost entirely overlooked in the current tobacco control framework.

The current study sought to examine smoking behaviour among young adults in Canada, with three specific objectives: (1) to compare patterns of use between young adults, youth, and older adults; (2) to characterise sex differences in smoking among young adults; and (3) to identify "high risk" groups of young adults across occupational settings. The policy implications of these findings are discussed, along with priorities for future research.

\section{METHODS}

\section{Procedure}

The current analysis used data from cycle 1 of the 2003 Canadian Tobacco Use Monitoring Survey (CTUMS). ${ }^{24}$ CTUMS is a national telephone survey of smoking behaviour administered by Statistics Canada to monitor trends in smoking prevalence. Data for the current analysis were drawn from interviews conducted between February and June of 2003.

Respondents were 15 years of age and over, excluding full time residents of institutions and residents of Canada's three territories. The sample design was a two stage stratified random sample of telephone numbers. In the first phase, households were selected as the primary sampling unit using random digit dialling. In the second phase, respondents were selected based upon household composition; where more than one individual in a household was eligible in an age group, the respondent was selected at random. Individuals aged 15-24 years were over-sampled in order to examine prevalence and smoking initiation among young Canadians.

Survey weights were used to adjust for non-response between provinces and groups, thereby minimising any bias in the analyses caused by differential response rates across different regions or groups. A full description of the sampling design and survey statistics is available. ${ }^{24}$

\section{Measures}

Individuals responded to a 20 minute survey of smoking behaviour. Smoking status was determined by asking, "At the present time do you smoke cigarettes every day, occasionally, or not at all?". Respondents were then asked whether they had smoked in the last 30 days and, if so, whether they smoked daily, weekly, or less than weekly. All respondents were asked whether they had smoked 100 cigarettes in their lifetime. Both current and former smokers were asked about quit attempts in the past two years and age of first cigarette. Intention to quit among occasional and daily smokers was assessed by asking, "Are you seriously intending to quit within the next six months/30 days?". Occasional and daily smokers were also asked to report their cigarette consumption for each of the previous seven days. Time to first cigarette was assessed by asking, "How soon after you wake up do you smoke your first cigarette?". Finally, occasional and daily smokers were asked to report the "strength" of cigarettes they usually smoke. Responses were coded as ultra/extra light/mild, light/mild, or regular strength.

\section{Analysis}

CTUMS data was weighted on sex, age, and province, followed by adjustments for non-response and multiple telephone lines within a household. All data reported in the results are weighted. (Note that weights were scaled to the sample size before analysis.) In addition, variance estimates were adjusted using "coefficients of variation" to take the survey's design effect into account. ${ }^{24}$ "Current smokers" were defined as respondents who reported smoking more than 100 cigarettes lifetime and at least once in the past 30 days. "Daily smokers" were defined as respondents who reported smoking daily. "Occasional smokers" were defined as nondaily smokers who smoked at least once in the past 30 days. "Former smokers" were defined as those who reported smoking 100 cigarettes, but had not smoked in the past 30 days. "Ever smokers" include both former and current smokers. "Young adults" were defined as respondents between the ages of 18 and 29 years, inclusive. This age range is somewhat different than the more traditional age range of 20-24 often used to define young adults; however, the purpose of the current analysis was to examine smoking over the full span of young adulthood. Further, there are strong conceptual grounds for considering 18 and 19 year olds as young adults, considering that 18 is the age of majority in most jurisdictions and that the lifestyle of most 18 and 19 year olds is more similar to other young adults than those 15-17 year olds. Likewise, the lifestyles of 25-29 year olds is much closer to "young adulthood" compared with older adults. All analyses were conducted using SPSS Version 12.0 (SPSS Inc, 2003).

\section{RESULTS}

\section{Smoking behaviour}

A total of 10559 Canadians responded to the survey, including 3812 respondents between the ages of 18-29 years, for a response rate of $89.8 \%$. Overall, $20.0 \%$ of Canadians were current smokers in 2003. Table 1 provides the characteristics for current smokers.

Table 2 indicates smoking prevalence and cigarettes per day by age group. A total of $28.3 \%$ or 1.38 million Canadians aged 18-29 were current smokers-the highest prevalence of any age group. On average, current and former smokers tried their first cigarette at 14.8 years of age, while $19.3 \%$ smoked their first cigarette after the age of 18. Daily smokers were less likely to try their first cigarette after the age of 18 compared to occasional smokers ( $16.6 \% v 10.7 \%$, respectively; $\left.\chi^{2}=3.6, \mathrm{p}=0.06\right)$. Among smokers over the age of 25 , there was a positive correlation between age of smoker and age of initiation $(r=0.29, \mathrm{p}<0.001)$.

Differences in smoking behaviour between male and female young adults were generally modest: females were somewhat more likely to be daily smokers $\left(\chi^{2}=6.1\right.$, $\mathrm{p}=0.013)$, and reported fewer cigarettes per day $(t=5.7$,

Table 1 Characteristics of current smokers in Canada. ( $n=10559$ )

\begin{tabular}{ll}
\hline Variable & Mean/proportion (SD) \\
\hline Mean age (years) & $38.9(14.7)$ \\
Sex (male) & $53.7 \%$ \\
Education (minimum 12 years) & $67.7 \%$ \\
Mean cigarettes per day & $13.5(9.5)$ \\
Intention to quit (within 6 months) & $55.6 \%$ \\
\hline
\end{tabular}




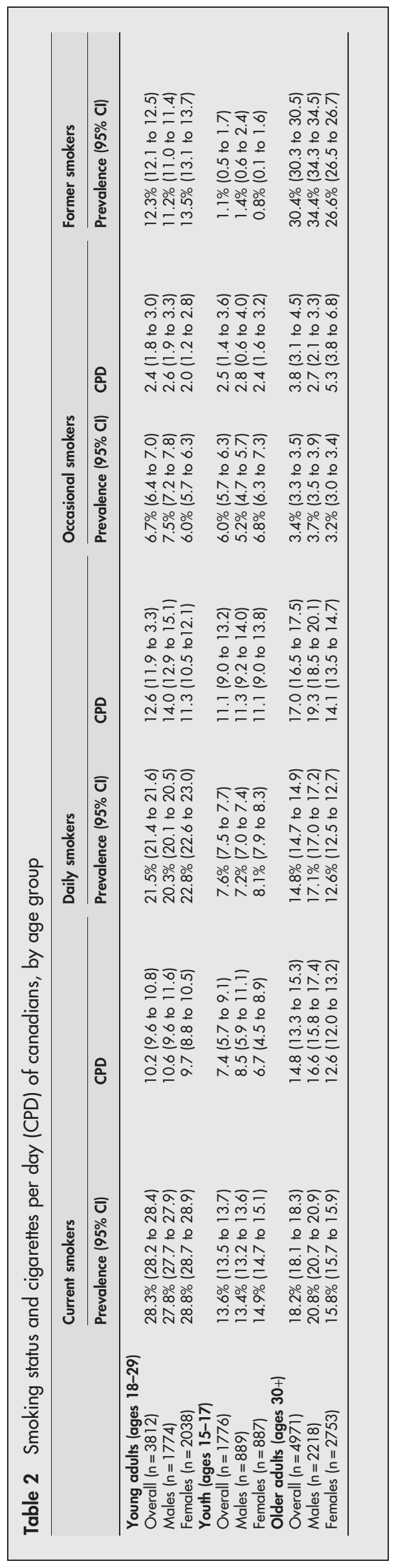

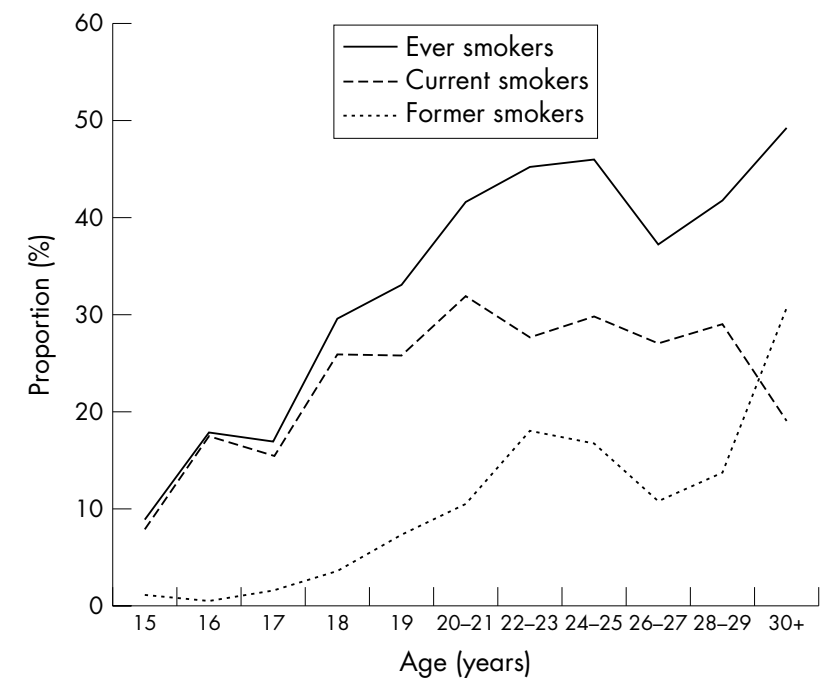

Figure 1 Prevalence of current, former and ever smokers, by age group.

$\mathrm{p}<0.001)$. There were no differences in the age of initiation between male and female young adult smokers.

Cigarettes per day (CPD) was $38 \%$ greater among young adults than youth $(t=2.5, \mathrm{p}=0.01)$. Daily consumption was stable during young adulthood at slightly over nine CPD, except for a modest increase in cigarettes per day among 2627 year olds. Time to the first cigarette of the day varied across age groups: approximately $36.9 \%$ of youth, $42.9 \%$ of young adults, and $64.4 \%$ of older smokers smoked within 30 minutes of waking $\left(\chi^{2}=67.1, \mathrm{p}<0.001\right)$.

Young adults were more likely to smoke light/mild cigarettes $(66.9 \%)$, than either youth $(61.2 \%)$, or older adults $\left(40.5 \% ; \chi^{2}=13.3, p=0.001\right)$. Young adult females were somewhat more likely to smoke "light/mild" brands than males $\left(69.1 \% v 64.7 \% ; \chi^{2}=3.7, \mathrm{p}=0.06\right)$.

Figure 1 depicts the proportion of ever, current, and former smokers by age group. The largest single year increase in prevalence occurred between the ages of 17 and 18, from $13.6 \%$ to $25.8 \%$ among 18 year olds. Smoking prevalence peaked at 21 years of age $(35.6 \%)$, while occasional use was highest among 24 years old at $11.3 \%$ (data not shown).

Approximately $56 \%$ of all young adults reported that they were seriously considering quitting within the next six months, $31 \%$ of whom were considering quitting within the next 30 days. Males were somewhat more likely to intend to quit within six months $\left(62.1 \% v 55.6 \% ; \chi^{2}=4.7, \mathrm{p}=0.03\right)$ and 30 days $\left(64.7 \% \vee 50.0 \% ; \chi^{2}=13.9, \mathrm{p}<0.001\right)$ than were females. A total of $64.6 \%$ of young adult smokers had attempted to quit smoking within the last two years.

\section{Occupational status and smoking}

Approximately $32.8 \%$ of all young adults were students in the past year, while $56.7 \%$ reported working. As table 3 indicates, smoking prevalence was lowest among students, professionals, and administrative/clerical workers. However, given that approximately one third of all young adults were students, students accounted for one quarter of all young adult smokers, far more than any other single workplace category. Among smokers, students smoked fewer cigarettes per day than those working $(8.1 \vee 10.8, t=5.3, \mathrm{p}<0.001)$.

\section{DISCUSSION}

This study demonstrates that young adulthood is a critical period in the development of smoking behaviour. 
Table 3 Smoking prevalence among young adults by employment status $(n=3812)$

\begin{tabular}{|c|c|c|c|c|}
\hline Occupation & Current smokers & $\begin{array}{l}\text { Proportion of all young adult } \\
\text { smokers }\end{array}$ & Former smokers & Quit rate per current smoker* \\
\hline Student & $21.6 \%(21.5$ to 21.7$)$ & $24.9 \%(24.9$ to 25.0$)$ & $6.9 \%(6.7$ to 7.1$)$ & 24.2 (24.1 to 24.3 ) \\
\hline Working (all occupations) & $31.4 \%(31.3$ to 31.5$)$ & $62.6 \%(62.5$ to 62.7$)$ & $12.8 \%(12.6$ to 13.0$)$ & $28.9(28.8$ to 29.0$)$ \\
\hline Sales/service & $35.9 \%(35.8$ to 36.0$)$ & $15.3 \%(15.1$ to 15.5$)$ & $13.0 \%(12.8$ to 13.2$)$ & $27.2(27.1$ to 27.3$)$ \\
\hline Trades/transport & $35.3 \%(35.1$ to 35.5$)$ & $9.2 \%(9.0$ to 9.4$)$ & $6.7 \%(6.5$ to 6.9$)$ & $15.8(15.6$ to 16.0$)$ \\
\hline Management & $35.5 \%(35.3$ to 35.8$)$ & $6.4 \%(6.2$ to 6.6$)$ & $3.9 \%(3.6$ to 4.2$)$ & $9.8(9.5$ to 10.1$)$ \\
\hline Technical & $31.1 \%(31.0$ to 31.2$)$ & $8.0 \%(7.8$ to 8.2$)$ & $12.6 \%(12.4$ to 12.8$)$ & $28.8(28.6$ to 29.0$)$ \\
\hline Professional & $22.7 \%(22.5$ to 22.9$)$ & $5.5 \%(5.2$ to 5.8$)$ & $14.3 \%(14.1$ to 14.5$)$ & 38.6 (38.4 to 38.8$)$ \\
\hline Administrative/clerical & $13.3 \%(13.1$ to 13.5$)$ & $2.5 \%(2.1$ to 2.9$)$ & $14.4 \%(14.2$ to 14.6$)$ & $52.0(51.9$ to 52.1$)$ \\
\hline Farming/forestry/fishing & $38.5 \%(38.2$ to 38.8$)$ & $2.2 \%(1.8$ to 2.6$)$ & $14.9 \%(14.5$ to 15.3$)$ & $27.9(27.6$ to 28.2$)$ \\
\hline Processing/manufacturing & $36.5 \%(36.3$ to 36.7$)$ & $5.7 \%(5.4$ to 6.0$)$ & $36.1 \%(36.0$ to 36.2$)$ & $49.7(49.5$ to 49.9$)$ \\
\hline Other working & $45.7 \%(45.5$ to 45.9$)$ & $7.3 \%(7.0$ to 7.6$)$ & $9.9 \%(9.7$ to 10.1$)$ & $17.8(17.6$ to 18.0$)$ \\
\hline Raising family/household & $32.2 \%(32.1$ to 32.3$)$ & $7.9 \%(7.7$ to 8.1$)$ & $27.4 \%(27.3$ to 27.6$)$ & $46.0(45.9$ to 46.1$)$ \\
\hline Looking for work & $31.1 \%(30.9$ to 31.3$)$ & $2.4 \%(2.0$ to 2.8$)$ & $10.7 \%(10.5$ to 10.9$)$ & $25.6(25.3$ to 25.9$)$ \\
\hline Other/refused & $56.9 \%(56.8$ to 57.0$)$ & $3.4 \%(3.1$ to 3.7$)$ & $6.7 \%(6.5$ to 6.9$)$ & 10.5 (10.3 to 10.7$)$ \\
\hline
\end{tabular}

Approximately $28 \%$ of young adults in Canada smoke-the highest prevalence of any age group and more than double the proportion of youth smokers. The findings also provide evidence of late initiation: approximately one fifth of current young adult smokers tried their first cigarette after the age of 18 years. Furthermore, regardless of when they first tried smoking, the majority of young adults became regular smokers after the age of 18. Indeed, the proportion of daily smokers increased dramatically from $8 \%$ among youth to $22 \%$ among young adults. The increase in "ever-smokers" (current and former smokers), is even more striking: 15\% of youth were ever smokers, compared with $40 \%$ of young adults-an increase of $267 \%$. Young adults were also heavier smokers than youth; cigarettes per day was 38\% greater among young adults and they were more likely to smoke within the first 30 minutes of the day. With regards to smoking cessation, the results suggest that successful attempts to quit smoking are relatively rare among youth, but increase sharply after the age of 17. Despite the rise in cessation among young adults, smoking prevalence continued to increase until age 22 , indicating that a greater number of new smokers replaced those who had quit.

Together, these findings suggest that both the proportion and intensity of smoking rise substantially after the age of 17 . Previous data suggest that this pattern of smoking is not a new phenomenon in Canada, but that it may be increasing to some extent. For example, CTUMS data from the past five years indicate that the prevalence of youth and young adult smoking may be diverging somewhat, suggesting that a greater proportion of young adults may be initiating daily or occasional smoking after the age of $20 .{ }^{25}$ These patterns are consistent with published data in the USA, ${ }^{45}$ although longitudinal and cohort analyses are necessary to examine these trends more closely.

Smoking behaviour among young adults also appears to be somewhat distinct from older smokers. Young adults were more likely to be occasional smokers than older adults, smoke fewer cigarettes, and to wait longer before smoking their first cigarette of the day. The difference in cigarettes per day between young adults and older smokers could suggest that cigarette consumption continues to increase beyond the age of 29, as might be expected from increasing tolerance; however, consumption continued to rise even after age 44 , beyond the point at which tolerance is typically established. As a consequence, the relationship between CPD and age may also reflect a cohort effect: daily consumption has been declining among Canadian smokers over the past decade following price increases ${ }^{26}$ which have been shown to have a relatively larger impact upon younger, less established smokers. ${ }^{27}$
The findings also demonstrate considerable heterogeneity in smoking among young adults. Smoking among students, professionals, and administrative/clerical workers was substantially lower than in the primary industries and trades. This pattern is generally consistent with the well established relationship between lower socioeconomic status and higher smoking: youth from lower socioeconomic backgrounds are more likely to smoke and less likely to attend university or college and become professionals. ${ }^{28}$ However, this does not rule out the possibility that work and school environments help to sustain or, conversely, to reduce smoking. Indeed, there is evidence that approximately one third of youth report that they first started smoking at work. ${ }^{29}$

The current results also suggest that smokers may not be quitting at the same rate in different occupations. This finding may reflect an interaction between sociodemographic variables and tobacco control policies: young adults in lower income occupations may be more likely to quit when cigarette prices are high or in occupational settings where smoking is either impractical or more likely to be restricted by workplace legislation. These results may prove useful for interventions seeking to target occupations with high prevalence rates, as well as those with a high proportion of smokers per work setting. For example, although those working in the "primary" industries reported the highest smoking prevalence, they are scattered across thousand of different work settings, while almost one quarter of all young adult smokers in Canada can be found in several dozen postsecondary institutions.

Overall, these findings are consistent with previous evidence indicating that young adulthood is a critical period when smoking is either rejected or becomes established as a long term addiction with substantial health risks. ${ }^{15} 15$ There are, however, several limitations of this study that should be noted. First, the cross sectional nature of the findings cannot detect trends over time or discriminate cohort effects. Second, the study lacks sufficient power to examine sex differences within subgroups, such as occupational settings. Finally, although there are considerable advantages to keeping the mode of survey administration consistent for all respondents, the measurement bias associated with telephone surveys of smoking behaviour may not be systematic across all age groups. Indeed youth tend to under-report smoking behaviour in telephone surveys to a greater extent than adults. ${ }^{30}$ As a consequence, some of the differences in smoking behaviour between youth and young adults may be due to differential response biases. However, this effect will be moderated somewhat among the older sample of youth surveyed in the current study and by the fact that parental consent was not required by CTUMS. 


\section{What this paper adds}

Smoking prevention programmes have focused almost exclusively upon youth, based upon the widespread assumption that smoking behaviour is largely established by the age of 18 years. In contrast, young adults have received little attention from either tobacco control programmes or researchers.

The current findings demonstrate dramatic increases in the proportion and intensity of smoking after the age of 18 . The prevalence of daily smoking nearly tripled from $8 \%$ among youth to $22 \%$ among young adults, despite significant increases in cessation. Overall, the findings suggest that smoking behaviour among young adults is distinct and represents untapped opportunities for tobacco control.

\section{Conclusions}

After two decades of impressive declines, there are growing concerns that smoking prevalence may be levelling off and stabilising. At the same time, a lack of effectiveness among traditional school based interventions has prompted a general review of smoking prevention strategies. ${ }^{20} 3132$ Findings from the current study suggest that young adults may represent the best opportunity for further reductions in prevalence and should be considered a priority within this review. Indeed, the same factors that increase receptivity to pro-tobacco messages among young adults-new social environments, peer groups, and values-also afford opportunities for prevention and cessation. However, to effectively target young adults, tobacco control strategy must reflect the reality of smoking initiation depicted in the current results more closely: trying a cigarette for the first time is not the last step in becoming a smoker, but rather the beginning of a process that for the majority stretches into young adulthood. Ultimately, the tobacco control community should heed the advice of the tobacco industry more closely: "Young adult smokers have been the critical factor in the growth and decline of every major brand and company over the last 50 years. If younger adults turn away from smoking, the industry will decline, just as a population which does not give birth will eventually decline." ${ }^{\prime 33}$

\section{ACKNOWLEDGEMENTS}

I would like to thank Jennifer Anne Topham, Michael K Cummings, and Geoffrey $\mathrm{T}$ Fong for their assistance with this manuscript. I would also like to acknowledge funding support from the Canadian Tobacco Control Research Initiative (CTCRI) and the Canadian Institute for Health Research (CIHR) Strategic Tobacco Research Training Program.

Competing interests: none declared

Ethics clearance: This research was reviewed and received ethics clearance from the Research Ethics Board at the University of Waterloo.

\section{REFERENCES}

1 Backinger CL, Fagan P, Mathews E, et al. Adolescent and young adult tobacco prevention and cessation: current status and future directions. Tobacco Control 2003;12(suppl IV):iv46-53.

2 Giovino GA. Epidemiology of tobacco use among US adolescents. Nicotine Tob Research 1999;1(suppl 1):31-40.

3 US Department of Health and Human Services. Preventing tobacco use among young people. A report of the Surgeon General, 1994. Atlanta, Georgia: Public Health Service, Centers for Disease Control and Prevention, Office on Smoking and Health, 1994 (US Government Printing Office Publication No S/N 017-001-00491-0.).

4 US Department of Health and Human Services. Cigarette smoking among adults-United States, 1965-1996. Centers for Disease Control and Prevention. MMWR Morb Mortal Wkly Rep 1998;47:837-48.

5 Lantz PM. Smoking on the rise among young adults: implications for research and policy. Tobacco Control 2003;12(suppl I):i60-70.

6 Hall LW. Early warning system input-reasons for smoking, initial brand selection, and brand switching. 25 Oct 1976. R.J. Reynolds Tobacco
Company. Bates No. 501103147-3150. http://

www.legacy.library.ucsf.edu/tid/hae59d00 (Accessed 6 July 2004).

7 Johnston ML, Daniel BC, Levy CJ. Young smokers prevalence trends, implications, and related demographic trends. 31 Mar 1981. Philip Morris USA. Bates No. 1000390803/0855. http://www.legacy.library.ucsf.edu/ $\mathrm{tid} / \mathrm{ftu} 74 \mathrm{e} 00$ (Accessed 6 July 2004)

8 Young \& Rubicam. Chesterfield. Phillip Morris Tobacco Company. 24 March 1994. Bates No. 2500086977/7024. http://www.legacy.library.ucsf.edu/ $\mathrm{tid} / \mathrm{mxl19e00}$ (Accessed 6 July 2004).

9 Business Information Analysis Corporation. RJR young adult motivational research. 10 Jan 1985. R.J. Reynolds Tobacco Company. Bates No. 502780379-0424. http://www.legacy.library.ucsf.edu/tid/xng78d00 (Accessed 6 July 2004).

10 Teague CE. Research planning memorandum on some thoughts about new brands of cigarettes for the youth market. 2 Feb 1973. R.J. Reynolds Tobacco Company. Bates No. 502987357-7368. http://

www.legacy.library.ucsf.edu/tid/act68d00 (Accessed 6 July 2004)

11 Anon. Young adult male smokers and young adult female smokers. Nov 1993. Philip Morris Tobacco Company. Bates No. 2045180640/0775. http://www.legacy.library.ucsf.edu/tid/nvl55e00 (Accessed 6 July 2004).

12 Ling PM, Glantz SA. Why and how the tobacco industry sells cigarettes to young adults: evidence from industry documents. Am J Public Health 2002;92:908-16.

13 Hammond D, Costello MJ, Fong GT. Tobacco industry marketing and policy support among university students: findings from the campus tobacco survey. Presented at the Ontario Tobacco Control Conference, Toronto, Ontario, May, 2004.

14 Sepe E, Glantz SA. Bar and club promotions in the alternative press: targeting young adults. Am J Public Health 2002;92:75-8.

15 Biener L, Albers AB. Young adults: vulnerable new targets of tobacco marketing. Am J Public Health 2004;94:326-31.

16 Katz SK, Lavack AM. Tobacco related bar promotions: insights from tobacco industry documents. Tobacco Control 2002;11(suppl I):i92-101.

17 Altman DG, Levine DW, Coeytaux MD, et al. Tobacco promotion and susceptibility to tobacco use among adolescents age 12 through 17 years in a nationally representative sample. Am J Public Health 1996;86:1590-93.

18 Pierce JP, Choi WS, Gilpin EA, et al. Tobacco industry promotion of cigarettes and adolescent smoking. JAMA 1998;79:511-15

19 Hammond D, Cameron R, Cushman R, et al. Tobacco denormalization and youth: Findings from the Ottawa public health exposé campaign. Presented at the Ontario Tobacco Control Conference; Toronto, Ontario, May, 2004.

20 Health Canada. Federal Tobacco Control Strategy: a framework for action. Ottawa, Ontario: Health Canada, 2004, http://www.hc-sc.gc.ca/hecs-sesc/ tobacco/ftcs/index.html\#toc.

21 Centers for Disease Control and Prevention. Best practices for comprehensive tobacco control programs - August 1999. Atlanta, Georgia: US Department of Health and Human Services, Centers for Disease Control and Prevention, National Center for Chronic Disease Prevention and Health Promotion, Office on Smoking and Health, August, 1999.

22 US Department of Health and Human Services. Reducing tobacco use: a report of the Surgeon General. Atlanta, Georgia: US Department of Health and Human Services, Centers for Disease Control and Prevention, National Center for Chronic Disease Prevention and Health Promotion, Office on Smoking and Health, 2000.

23 Wechsler H, Rigotti NA, Geldhill-Hoyt J, et al. Increased levels of cigarette use among college students: a cause for national concern. JAMA 1998;280:1673-8.

24 Statistics Canada. Microdata user guide, Canadian tobacco use monitoring survey cycle 1 February-June 2003. Ottawa, Ontario: Statistics Canada, 2004, http://www.statcan.ca/english/Dli/Metadata/ctums/2003/cyclel/ ctums2003cl gid.doc.

25 Health Canada. Smoking in Canada: an overview. Annual Report FebruaryDecember 2002. Ottawa, Ontario: Health Canada, 2002, http://www.hcsc.gc.ca/hecs-sesc/tobacco/research/ctums/2002/pdf/Overview2002LA2.pdf.

26 Health Canada. Canadian tobacco use monitoring survey wave 12003 , supplementary tables. Tobacco Control Program. Ottawa, Ontario: Health Canada, 2004, http://www.hc-sc.gc.ca/hecs-sesc/tobacco/research/ ctums/index.html.

27 Chaloupka FJ, Wechsler H. Price, tobacco control policies and smoking among young adults. J Health Econ 1997;16:359-73.

28 Jarvis MJ, Wardle J. Social patterning of individual health behaviors: the case of cigarette smoking. In: Marmot M, Wilkinson RG, eds. Social determinants of health. Oxford: Oxford University Press, 1999

29 Borland R, Chapman S, Owen N, et al. Effects of workplace smoking bans on cigarette consumption. Am J Public Health 1990;80:178-80.

30 Kann L, Brener ND, Warren CW, et al. An assessment of the effect of data collection setting on the prevalence of health risk behaviors among adolescents. J Adolesc Health 2002;31:327-35.

31 Rooney BL, Murray DM. A meta-analysis of smoking prevention programs after adjustment for errors in the unit of analysis. Health Educ $Q$ 1996;23:48-64.

32 Peterson AV, Kealey KA, Mann SL, et al. Hutchinson smoking prevention project: long-term randomized trial in school-based tobacco use preventionresults on smoking. J Natl Cancer Inst 2000;92:1979-91.

33 Burrows D. Strategic Research Report: Young Adult Smokers - Strategies and Opportunities, RJ Reynolds Marketing Research. 29 February 1984. Bates No. 94684274/4360 http://www.legacy.library.ucsf.edu/cgi/ getdoc?tid $=$ rwa63a00\&fmt $=$ pdf\&ref $=$ results (Accessed 7 July 2004). 